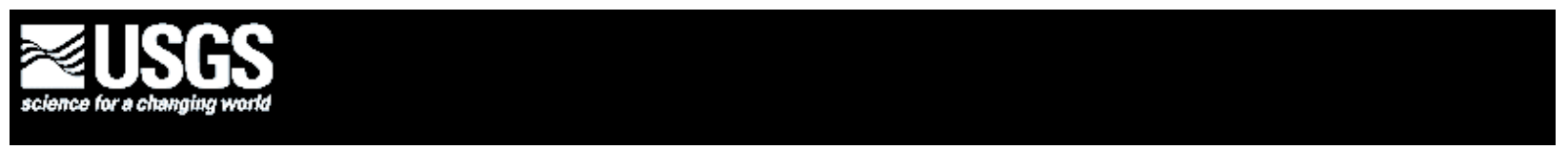

USGS Open File Report 2004-1454

\title{
Alaska North Slope Gas Hydrate Energy Resources
}

\section{By Timothy S. Collett}

In late November 2004, the Alaska State Legislature requested the U.S. Geological Survey (USGS) to provide a technical briefing on the energy resource potential of gas hydrates in northern Alaska at the Federal Energy Regulatory Commission (FERC) “Technical Conference for Regulations Governing the Conduct of Open Seasons for Alaska Natural Gas Transportation Projects, Docket No. RM05-1-000,” scheduled for December 3, 2004, in Anchorage, Alaska. In response to this request, Dr. Timothy S. Collett of the USGS participated in the FERC-hosted conference, and presented a brief overview of the energy resource potential of gas hydrates in northern Alaska. This report summarizes Dr. Collett's presentation at the conference, in which he discussed the issue under the FERC “Notice of Proposed Rule Making” that addresses the amount of Alaska North Slope gas potentially available for transport through an Alaska gas pipeline.

Gas hydrates are naturally occurring ice-like substances composed of water and gas. Gas hydrates are widespread in permafrost regions and beneath the sea in sediment of outer continental margins. The amount of natural gas sequestered in gas hydrates is probably enormous, but estimates of the amounts are highly speculative. In 1995, the USGS conducted the first systematic assessment of the in-place natural gas hydrate resources of the United States. That study suggested that the amount of gas in the Nation's hydrate accumulations greatly 
exceeds the volume of known conventional domestic gas resources. The 1995 USGS assessment also estimated that the permafrost-associated gas hydrates on the Alaska North Slope may contain as much as 590 trillion cubic feet of in-place gas (fig. 1).

Two large gas hydrate accumulations have been identified near the Prudhoe Bay Oil Field (fig. 2). The volume of gas estimated within the known gas hydrates of the Prudhoe BayKuparuk River infrastructure area alone may exceed 100 trillion cubic feet of in-place gas. However, it is important to note that none of the completed gas hydrate energy assessments have predicted how much gas could actually be produced from the known gas hydrate accumulations in northern Alaska.

Under the Methane Hydrate Research and Development Act of 2000, the U.S. Department of Energy (DOE) funds laboratory and field research on both Arctic and marine gas hydrates. Among the current Arctic studies, BP Exploration (Alaska), Inc. and the DOE have undertaken a project to characterize, quantify, and determine the commercial viability of gas hydrates and associated free gas resources in the Prudhoe Bay, Kuparuk River, and Milne Point field areas on the Alaska North Slope. Ultimately, this project could determine if gas hydrates can become a part of the Alaska North Slope gas-resource portfolio. Also in northern Alaska, the Bureau of Land Management, the Alaska Division of Geological and Geophysical Surveys, and the USGS are assessing the resource potential of gas hydrates over the entire area, including the National Petroleum Reserve Alaska, Arctic National Wildlife Refuge, and the State and Native lands north of the Brooks Range. The goal of this joint project is to assess the economically recoverable resource potential of gas hydrates and associated free gas accumulations in northern Alaska. 
The production potential of the Alaska North Slope gas hydrate accumulations has not been adequately tested. Although unverified by field testing, production models of gas hydratebearing reservoirs within prospects interpreted from seismic and well data in the Milne Point area (fig. 2) suggest that sustained production rates of several million cubic feet of gas per day can be achieved. In December 2003, the Canadian Mallik 2002 Gas Hydrate Production Research Well Program partners (including the USGS and the DOE) publicly released the results of the first modern, fully integrated field study and constrained production test of a natural gas hydrate accumulation. The Mallik 2002 gas hydrate production testing and modeling effort has, for the first time, enabled rational assessment of the production response of a gas hydrate accumulation. Project-supported gas hydrate production simulations have shown that under certain geologic conditions gas can be produced from gas hydrates at rates exceeding several million cubic feet of gas per day.

A growing body of evidence suggests that a huge volume of natural gas is stored as gas hydrates in northern Alaska and that production of natural gas from gas hydrates may be technically feasible. However, numerous technical challenges must be resolved before this potential resource can be considered an economically producible reserve.

\section{Figures}

Figure 1. This map depicts the area in northern Alaska in which subsurface temperature and pore-pressure conditions are conducive to the occurrence of gas hydrates. Also shown is the location of the Eileen and Tarn gas hydrate accumulations in the Prudhoe Bay area. NPRA = National Petroleum Reserve in Alaska; ANWR = Arctic National Wildlife Refuge. 
Figure 2. This map depicts the distribution of the Eileen and Tarn gas hydrate accumulations in the area of the Prudhoe Bay, Kuparuk River, and Milne Point oil fields on the North Slope of Alaska. 
Figure 1. This map depicts the area in northern Alaska in which subsurface temperature and pore-pressure conditions are conducive to the occurrence of gas hydrates. Also shown is the location of the Eileen and Tarn gas hydrate accumulations in the Prudhoe Bay area. NPRA = National Petroleum Reserve in Alaska; ANWR = Arctic National Wildlife Refuge.

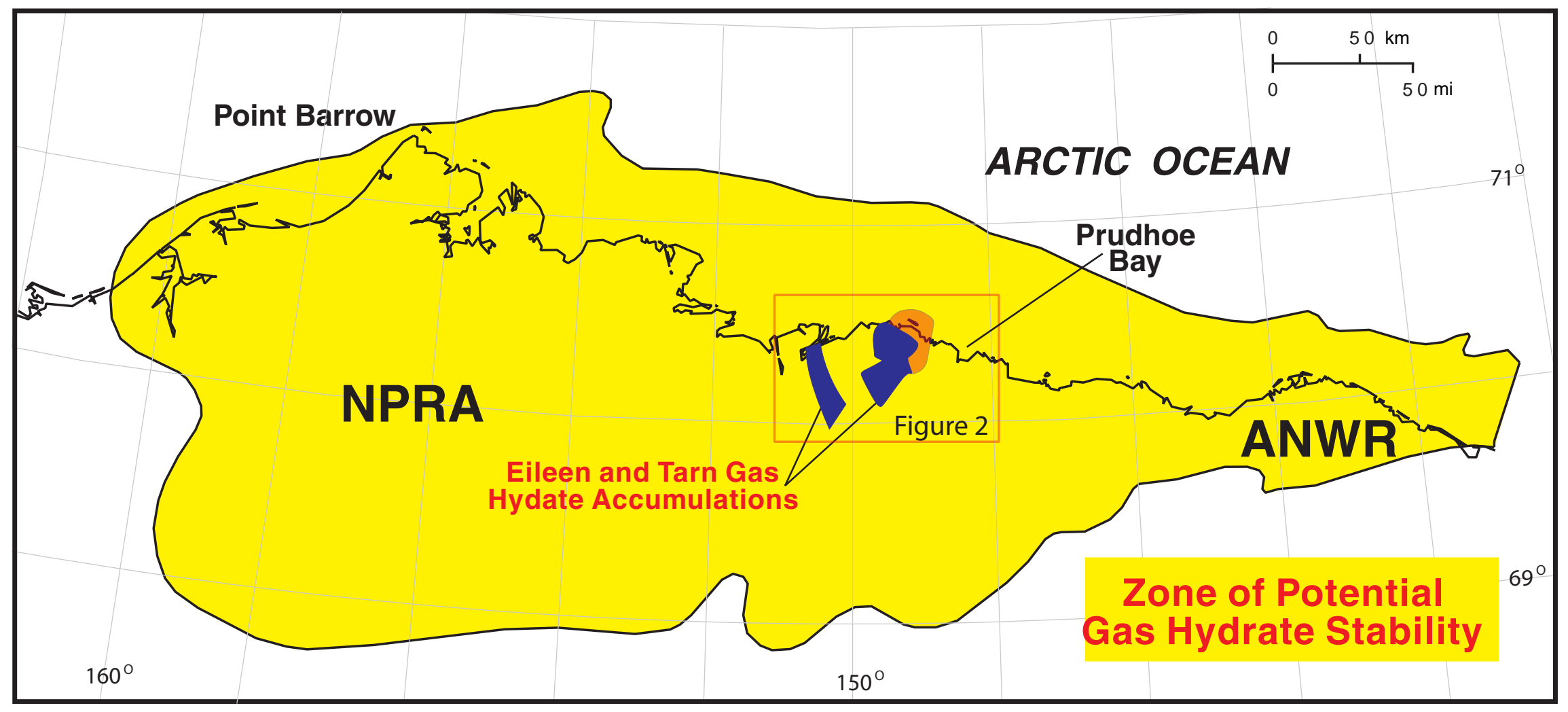


Figure 2. This map depicts the distribution of the Eileen and Tarn gas hydrate accumulations in the area of the Prudhoe Bay, Kuparuk River, and Milne Point oil fields on the North Slope of Alaska.

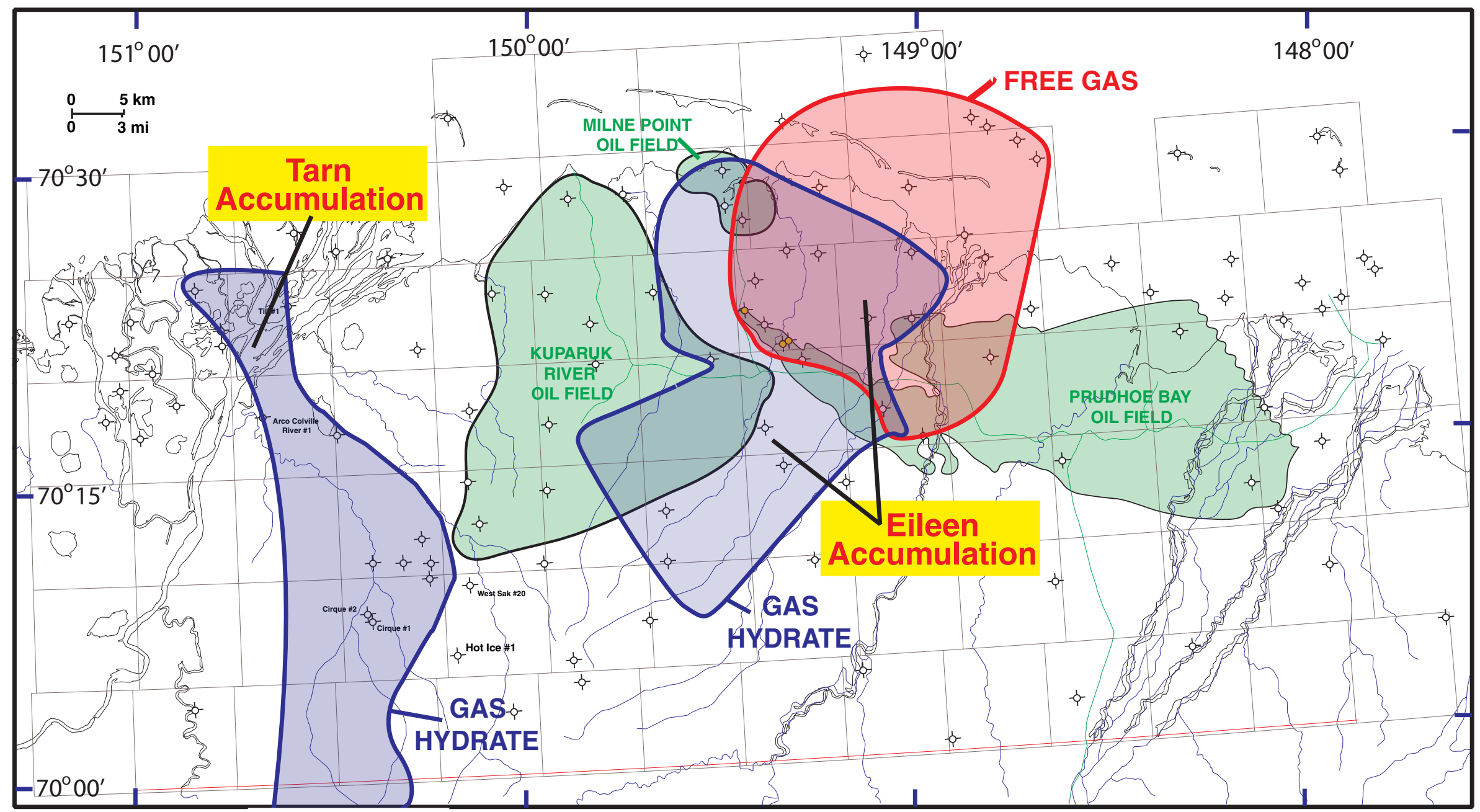

